Document downloaded from:

http://hdl.handle.net/10251/102171

This paper must be cited as:

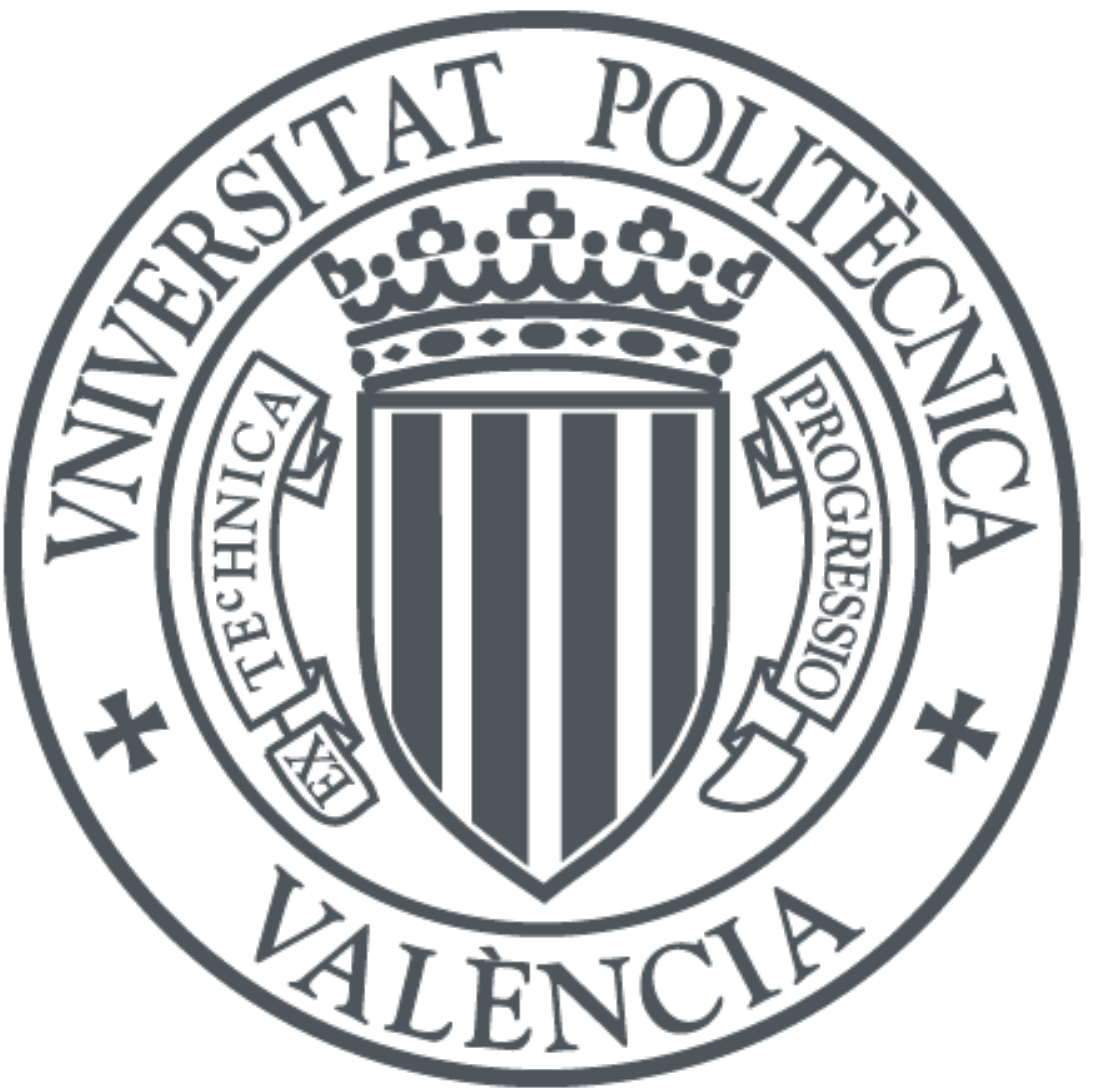

The final publication is available at

https://doi.org/10.1016/j.buildenv.2017.06.004

Copyright Elsevier

Additional Information 


\title{
Subjective assessment of university classroom environment
}

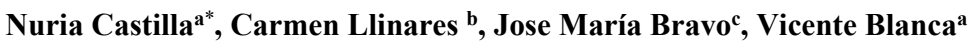 \\ ${ }^{a}$ Dpto. Construcciones Arquitectónicas, Universitat Politècnica de València, Camino de Vera, s/n, Valencia, 46022, \\ Spain. \\ ${ }^{\mathbf{b}}$ Instituto de Investigación e Innovación en Bioingeniería, i3B, Universitat Politècnica de València, Camino de Vera, \\ s/n, Valencia, 46022, Spain.

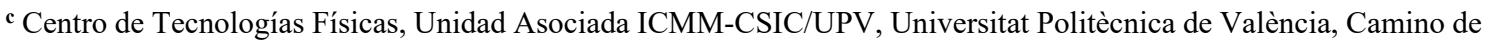 \\ Vera, s/n, Valencia, 46022, Spain. \\ * Corresponding author: Tel.: +34677807031. E-mail address: ncastilla@ csa.upv.es (Nuria Castilla)
}

\section{Highlights}

- Analysis of classroom design attributes that generate a positive affective response

- Use of Semantic Differential to identify students' affective impressions

- 918 university students assessed in situ 30 university classrooms.

- Classroom design should be directed at improving sensations of functionality and cosy.

\begin{abstract}
Research into the design of learning environments is warranted as the classroom space impacts on students' wellbeing and learning performance. Studies on subjective evaluation of classrooms usually focus on the influence of more objective aspects like temperature or light, based on concepts or attributes defined by experts. Thus, the attributes used to find relations with design parameters might not be recognised by users, thereby conditioning the evaluation process itself.
\end{abstract}

This paper aims to analyse students' affective response to a university classroom in their own words, and then, after obtaining the semantic space, to identify the design elements that generate a positive affective response. This analysis was carried out implementing the Semantic Differential method in the framework of Kansei Engineering. A sample of 918 university students was assessed in situ in 30 university classrooms.

The results show that students' affective structure in relation to their classroom comprises 6 independent factors: functionality and layout, cosy and pleasant, concentration and comfort, modern design, daylight and outward facing, and artificial lighting. From these 
factors, efforts to improve the classroom environment should be directed mainly towards two aspects: improving classroom functionality-layout, which is significantly related to the work space allocated to students; and the sensation of cosy-pleasant which is generated by all the classroom design parameters, but in particular, those that refer to the relationship of the classroom with the outdoor environment.

\section{Keywords}

Classroom attributes; Semantic Differential; Student perception; classroom environment; Kansei engineering; University classroom

\section{INTRODUCTION}

The learning environment needs attention as this space is related to students' well-being and learning performance [1]. Studies of school buildings have shown that factors of environmental comfort can greatly affect the learning process [2]. Indeed, the physical learning environment has a great impact on students' learning and motivation including the motivation to actively participate in academic activities [3]. Scott-Webber, Marini, and Abraham [4] found the relationship between classroom and learning environment significant because the built environment can influence behaviours. To facilitate learning, occupants must feel comfortable enough to take the individual and collective risks requisite to meaningful interaction and learning [5].

The literature on classroom design is huge and discusses classroom architecture in relation to educational theory and tendencies. Nevertheless, a lack of analyses comparing the results obtained by different authors is observed. Perhaps this is the reason why the connections between the design and use of space in higher education and the production of teaching, learning and research are not well understood [6]. In this sense, it is remarkable the investigation of Barret et al. [7][8] that identified seven key design parameters of the built environment that impact on learning progress and give 
some support for the importance of "inside-out design". In another study, Tanner [9][10] studied the relation between student outcomes and school's physical environment. The methodology followed in these works is based on the relation, for a very high sample, of the students' academic results with the physical environment of the classroom. In other works, the subjective component has been incorporated, including the students' perceptions from the assessment of the attributes of the classroom and also their possible impact on their performance or satisfaction. In this sense, Yang et al. [11] studied student perceptions of higher education classrooms and tried to establish the impact of classroom attributes on student satisfaction and performance. Hill and Epps [12] analysed the impact of physical classroom environment factors and found that differences in the physical characteristics of classrooms affected students' perceptions of their general sense of satisfaction. Asiyai [3], also gathered the students' response about the condition of classroom physical learning environment and its impact on learning and motivation. All these studies suggest a quantitative methodology. In contrast, with a qualitative proposal, Gislason [13] gathered the perceptions and other reactions of the students about their school environment using semi-structured interviews.

These examples show that studying the impact of classrooms on students is a complex problem. In the literature studies that examine in isolation specific physical and environmental factors with an impact on students are more numerous. One of the studied parameters is students' personal work space in relation to the size, functionality, arrangement and layout of the classroom, the sense of "ownership" of space and equipment [14] and furniture (type, distribution, flexibility, etc.)[15]. Ducanson [16] reports on the importance of students' work space and relates it to the fact that the space 
in a room delivers a silent message to students, where the flow and shift of distance between people is part of the communication process. Another important aspect is Indoor environmental quality (IEQ) which includes physical environmental parameters such as thermal comfort (TC), indoor air quality (IAQ), visual comfort (VC) and acoustic comfort (AC) [17]. Others investigations study the relationships between IEQ in classrooms and students well-being [1][18], comfort [19], concentration [20], and learning performance [21][22]. The mechanism underlying this effect is that poor IEQ could affect students' health and well-being, leading to absenteeism and a reduction in their academic performance [23][24] [25][26].

Another significant parameter is the relationship of the classroom with the outside, determined mainly by the openings in the room. Research supports the positive effects of daylight [27][28][29][30] and views of nature, the external world and contact with outdoor spaces [31][32][33]. Another of the studied aspects are the finishes in the classroom, not only in terms of materials but also colour, aesthetics, and even the state of upkeep. In the case of colour, researchers have focused on finding out whether colour can affect students' mood [34], behaviour [35], attention [36], performance [37], productivity [38] and academic achievement [39]. Design, condition, and state of upkeep have also been analysed, both of the classroom and the building enveloping it and their relationship with academic achievement [40][41].

From a methodological perspective, most of the works reviewed collect student responses using assessment questionnaires. Such questionnaires usually have assessment scales defined a priori by researchers or experts [42][43][44][45] which may not correspond to the interviewees' conceptual structure. This approach may represent a 
significant limitation, because the concepts used in the scales may be wrongly interpreted by interviewees and thus impair the assessment process. If the ultimate aim is to evaluate students' perceptions of the classroom space, researchers need to know how they express that perception so that after identifying their conceptual structure, it can be related to the design elements.

The technique used in this study is based on the Semantic Differential method (SD). SD is a useful tool for measuring subjective responses to concepts and provides a quantitative measure for the affective meaning of design concepts [46]. Originally, it was developed by Osgood et al. [47] to analyse relationships between attributes or adjectives and design parameters which are wholly defined by the user. Thus, this technique studies product semantics by means of adjectives and expressions which reflect users' affective impressions and measures users' perceptions on a Likert scale. If it can be demonstrated that a limited number of dimensions or factors is sufficient to differentiate between the meanings of the whole set of concepts, then these dimensions define a semantic basis for expressing any product. This semantic basis is known as semantic space and each concept is a factor or semantic axis. This technique is one of the most commonly used methods for assessing product perception in Kansei Engineering.

Kansei Engineering (KE) is a methodology used to quantify consumer's perceptions and relate them to design criteria [48]. KE was developed in the 1970s at the Kure Institute of Technology (Hiroshima, Japan). The aim of this technique is to identify and quantify users' perceptions of a product in their own language and to find quantitative relationships between these subjective responses and design features [48][49]. Other 
techniques can be used to translate consumer or user needs and preferences into product design characteristics, such as Quality Function Development [50][51] or Conjoint analysis [52]. KE has some advantages over these techniques, however, because it establishes a suitable framework for working with the symbolic attributes and perceptions of users, expressed in their own words. Other techniques base product development on user preferences for functional aspects considered in terms defined by experts. KE is based on the fact that an individual's perceptions are not only influenced by the stimuli but also by the conceptual scheme of a concrete group of users (semantic space). Thus, this technique can be used to quantify users' perceptions of a product in their own language and relate these subjective responses to particular design features.

The introduction of a KE methodology requires two phases [53]. In the first phase, users' perceptions must be captured in their own words to obtain the set of independent concepts (semantic space or semantic axes) they use to describe their sensations in relation to the product. This semantic space forms an important tool for measuring an independent product or comparing different products from the perspective of their symbolic attributes. In the second phase, and after obtaining users' affective dimensions or semantic axes, attempts are made to identify what design elements cause these semantic axes or perception variables.

Many studies have used SD in the framework of KE to analyse users' perceptions of a multitude of products: automotive industry [48][54], building sector [55][56], housing design [57][58], urban design [59], acoustic and sound perception [60][61][62] and thermal environment [63][64]. Nevertheless, to our knowledge, there are very few examples of the application of KE to classrooms with the aim of measuring students' 
responses. For example, the study of Şenol-Erdoğmuş [65] suggests a KE algorithm to measure the effect of the design elements of the classroom on the students' motivation feeling. Using ordinal regression analysis, the study identified the most important design elements (teacher's desk, lighting, ventilation, and curtains) and the design goals related to these elements. The students' assessment was focused on the contribution of each design element to the motivation feeling. Our proposal, however, is aimed at incorporating to this approach the student's affective response to the classroom environment. This allows us to identify not only which design elements are important in the global assessment of the classroom, but also the affective response that they generate.

In this way, the general aim of this study is to identify design elements with a positive impact on students' affective impressions generating a favourable overall assessment. The study has two clearly differentiated stages in the framework of Kansei Engineering (Figure 1). The initial stage attempts to identify the set of affective impressions relevant in the global assessment of the classroom, applying SD. The second stage aims to identify the classroom design elements with the greatest impact on those affective impressions.

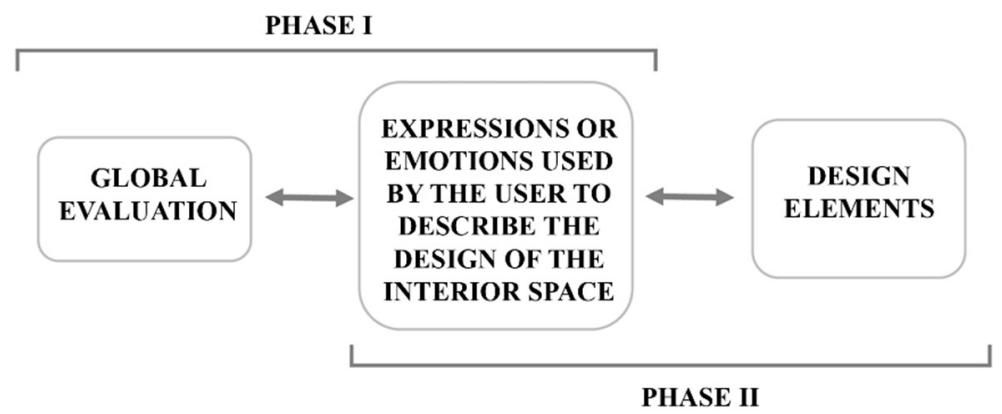

Fig. 1. Kansei Engineering approach. 


\section{MATERIAL AND METHODS}

The methodological development focused on a field study which collected students' evaluations of their own classroom.

\subsection{Subjects}

The participants were 918 students, habitual users of the classrooms being evaluated. Average age of the students was 22.45 years with a standard deviation of 4.83 . In the sample $76.8 \%$ of individuals were between 19 and 24 years old (Table 1).

\begin{tabular}{llcc}
\hline Gender & Male & 490 & $53.39 \%$ \\
& Female & 428 & $46.61 \%$ \\
\hline Age & $<20$ & 170 & $18.52 \%$ \\
& $20-25$ & 633 & $68.95 \%$ \\
& $26-30$ & 71 & $7.73 \%$ \\
& $31-40$ & 24 & $2.61 \%$ \\
& $>40$ & 20 & $2.18 \%$ \\
\hline
\end{tabular}

Table 1. Data of the subjects participating in the field study

\subsection{Stimuli}

The stimuli for the field study consisted of 30 university classrooms in 11 different buildings, on two university campuses in the region of Valencia (Spain). Selection criteria for this sample were that the number of classrooms and their characteristics made the sample sufficiently representative and differentiated. Semantic axes are extracted by establishing relationships between many variables, and so responses in a broad range of opinions are needed. Thus, users are required to judge a sample of classrooms with a variety of characteristics: different height classrooms, surface areas, location, layout, indoor environmental quality, finishes and type of teaching (classrooms for theory and practical lessons, laboratory work and work on projects). The use of real 
rooms where it is impossible to change design characteristics may cause the appearance of confounding factors, thereby creating bias in the results. The solution adopted to reduce bias was to introduce the set of characteristics or attributes in a random fashion [66].

\subsection{Questionnaire}

The questionnaire comprised two blocks. The first block gathered objective information on the individual: age, sex, education. The second block contained subjective information about:

a) 26 variables that describe students' affective response to the classroom. The study followed the process established by Schütte et al. [53] and Llinares and Page [56]. The first step was to collect as many words and expressions as possible (from interviews with students, scientific documentation, specialized bibliography, internet, journals, and professional magazines) that people use to express classroom attributes. The idea behind collecting as many adjectives and expressions as possible was to collect a set of words capable of describing all possible perceptions of a classroom. In this phase, a total of 160 expressions were compiled. However, this number of words is too large to be included in a questionnaire. To decrease this set of adjectives the affinity diagram technique[67]was applied in focus group sessions with eight participants (two professors, two students, two architects and two Kansei experts). Affinity Diagram consists in forming groups of similar words and assigning one significant word to embrace all the expressions in the group. The process finishes when no new words appear. The affinity diagram reduced the initial list to 26 adjectives. This set of concepts or affective impressions were included in the questionnaire with the expression "In my opinion, the classroom is...." 
b) 20 design variables for the classroom were chosen. These attributes were obtained from a selection made during focus group sessions with the same eight individuals who participated in the session for grouping the affective descriptors. Basic design attributes related to the classroom were chosen. They included attributes related to the interior architecture, design, and Indoor Environmental Quality (IEQ) of the classroom. Initially, 84 design variables for the classroom were collected and using the affinity diagram technique [67] that initial list was reduced to 20 design variables. These design elements were included in the questionnaire with the expression "I think the following design elements in the classroom are appropriate"

c) In addition to these expressions, one variable in the questionnaire reflected the student's overall evaluation of the classroom obtained by the expression "Generally, I think the classroom is suitable".

All the adjectives were evaluated on a 5-point-Likert scale ranging from strongly disagree, disagree, neutral, agree and strongly agree. The questionnaire was validated after numerous pilot tests were conducted to ensure it could be finished in a reasonable amount of time and the wording and the sequencing of the questions were appropriate. This pre-testing process was carried out with 35 students.

\subsection{Development of the field study}

The field study collected interviewees' evaluations of the classroom where students had to evaluate the classroom in situ, and were thus "immersed" in the stimulus. It was decided to undertake the field study under these conditions rather than in the laboratory because lab conditions cannot represent real settings with $100 \%$ reliability. Students were personally informed of the study objectives although the questionnaire also included instructions on how to fill it in correctly. Participants were asked to complete 
the questionnaire as soon as the class had finished, thus ensuring they had been in the room long enough to assess it properly. Average time for completing the questionnaire was $10 \mathrm{~min}$. The order of the questions was randomized and five different models of questionnaire were created to avoid any bias in the subjects' responses.

\subsection{Data processing}

Data were processed statistically using SPSS software following the scheme shown in Table 2. The analysis was divided into two stages. In the first stage, the objective was to identify the set of significant affective impressions in the overall evaluation of the classroom and the second stage focused on obtaining the relationship between the elements of classroom design and affective impressions.

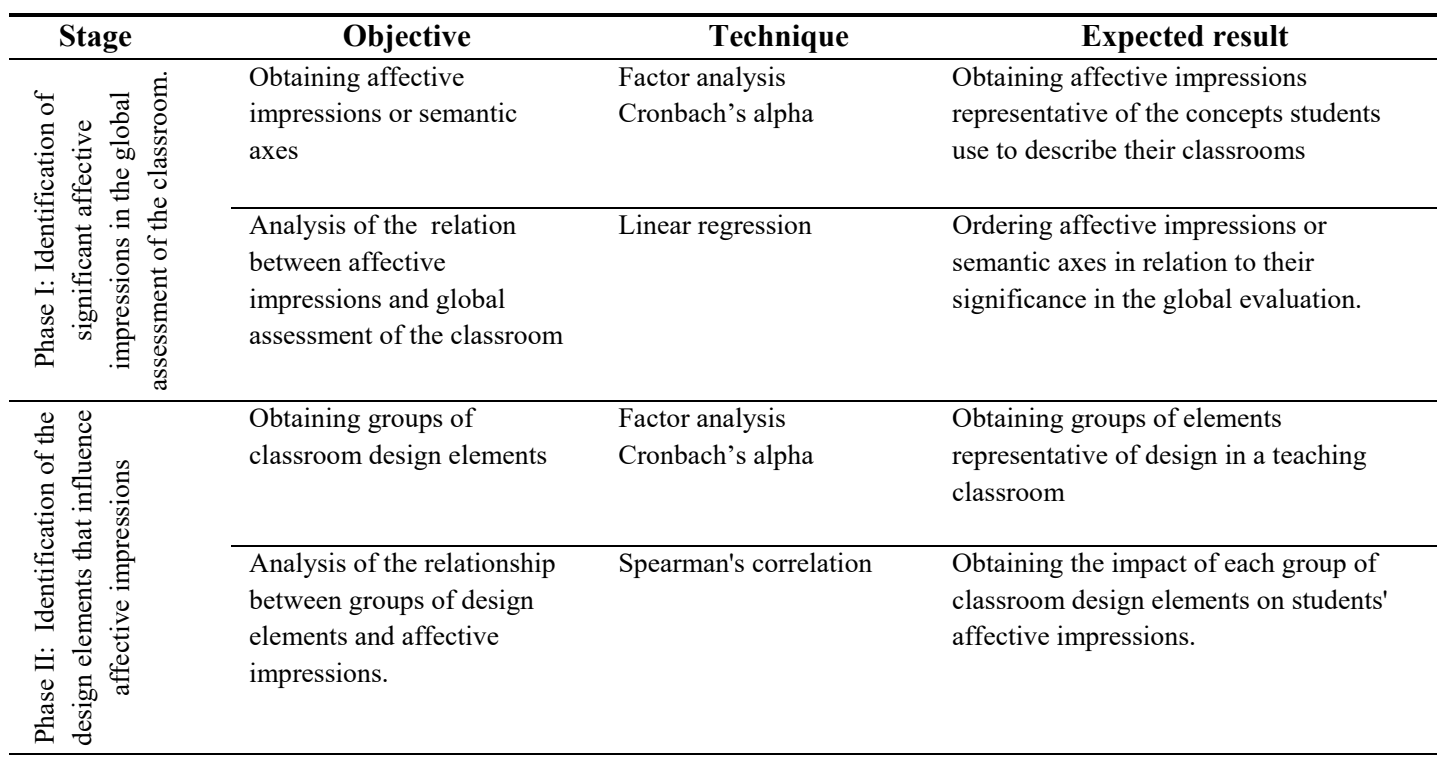

Table 2. Data processing stages, techniques and expected results

\section{RESULTS}




\subsection{Phase 1: Identification of significant affective impressions in the global assessment of the classroom}

\subsubsection{Obtaining affective impressions or semantic axes}

Factor analysis grouped the 26 expressions in the questionnaire into seven axes or factors. These semantic axes explain $64 \%$ of the variance (Table 3 ). The contribution of the original variables to the axis was analysed to determine the concept associated with each of them, thereby obtaining the following seven factors or dimensions:

- 1st factor: includes the perception of Functionality and layout of the classroom. It is the assessment of how far the classroom is suitable for its function or use and that it is tidy. The kansei words that contribute most to this factor are "well laid out", “well organised”, "spacious", “good furniture”, "good equipment”, “easy access", "well positioned", "good design" and "good ventilation" and the opposite of this factor, with negative correlations, is the adjective "oppressive". This factor explains $16.14 \%$ of the variance in the original variables.

- 2nd factor: represents the sensations of Cosy and pleasant evoked by the classroom. The adjectives in this axis refer to the perception of the classroom as "cosy", "cheerful" and "pleasant". It explains $10.17 \%$ of the variance.

- 3rd factor: represents the concepts of It helps me to concentrate and is comfortable. Expressions such as "silent", "helps me to concentrate", "good temperature", "comfortable" and "intimate" are very significant on this factor. It explains $10.16 \%$ of the sample variance.

- 4th factor: reflects the dimension Modern design with adjectives such as "new", "good design" and "good furniture". It explains $8.28 \%$ of sample variability. 
- 5th factor: includes the perception of Good daylight and outward facing in the classroom. It is the assessment of how far the classroom is well lit and relates appropriately with the outside. The kansei words that contribute most to this factor are "good daylight", "outward facing", "well lit”, "good ventilation", "good design", "easy access" and "cheerful". This factor explains $8.26 \%$ of the variance.

- 6th factor: represents Good artificial lighting with "good artificial lighting" and "well lit" as main concepts. It explains $6.21 \%$ of the sample variance.

- 7th factor: represents the dimension Humidity and explains $4.84 \%$ of the variance. The descriptors that contribute the most are "damp" and "oppressive".

\begin{tabular}{|c|c|c|c|c|c|c|c|}
\hline & 1 & 2 & 3 & 4 & 5 & 6 & 7 \\
\hline Well laid out & .761 & & & & & & \\
\hline Well organised & .688 & & & & & & \\
\hline Spacious & .677 & & & & & & \\
\hline Good furniture & .642 & & & .368 & & & \\
\hline Good equipment & 607 & & & & & & \\
\hline Easy access & .573 & & & & .350 & .365 & \\
\hline Oppressive & -.531 & & & & & & .436 \\
\hline Well positioned & .501 & & & & & .469 & \\
\hline Good design & .476 & & & .405 & .372 & & \\
\hline Good ventilation & .463 & & & & .420 & & \\
\hline Cosy & & .809 & & & & & \\
\hline Cheerful & & .740 & & & .327 & & \\
\hline Pleasant & .358 & .664 & & & & & \\
\hline Safe & & .585 & & & & & \\
\hline Silent & & & .745 & & & & \\
\hline Helps me to concentrate & & & .699 & & & & \\
\hline Good temperature & & & .697 & & & & \\
\hline Comfortable & .379 & .349 & .583 & & & & \\
\hline Intimate & & & .456 & & & & .423 \\
\hline Old & & & & -.868 & & & \\
\hline New & & & & .846 & & & \\
\hline Good daylight & & & & & .738 & & \\
\hline Outward facing/Exterior & & & & & .712 & & \\
\hline Good artificial lighting & & & & & & .760 & \\
\hline Well lit & & & & & .461 & .582 & \\
\hline Damp & & & & & & & .778 \\
\hline$\%$ Variance explained & 16.14 & 10.17 & 10.16 & 8.28 & 8.26 & 6.21 & 4.84 \\
\hline Cronbach's Alpha & 0.859 & 0.814 & 0.754 & 0.745 & 0.770 & 0.687 & 0.257 \\
\hline
\end{tabular}


Table 3. Factor analysis of affective impressions

Consistency of perceptual space was verified with Cronbach's Alpha. The values for this reliability coefficient for the first six dimensions ranged from 0.69 to 0.86 (Table 3), showing that these scales have considerable reliability [68].

3.1.2. Analysis of the relationship between affective impressions and global assessment of the classroom

Perception axes were ordered according to their relation with the variable 'global assessment of the classrooms' using regression analysis. The model (Table 4) includes six significant axes. The $\mathrm{R}$ coefficient is 0.765 so the model has good prediction ability. The axis with the greatest influence on the global evaluation of a classroom is perceptions of Functionality and layout (well laid out, tidy and with good furniture) with positive correlation over 0.50 . This axis is followed by perceptions of Cosy and pleasant (a classroom which is cosy, cheerful, and pleasant), Concentration and comfort (helps you to concentrate, is silent and has a good temperature), with Good artificial lighting (well lit) and with Good Daylight and good relationship with the outside (outward facing, well lit, good ventilation) with correlations in the interval $0.20-0.35$. Finally, perception of a classroom's Modern Design has a correlation of 0.104 .

\begin{tabular}{|l|c|c|c|c|c|}
\hline Model & B & $\begin{array}{c}\text { Standard } \\
\text { dev. }\end{array}$ & $\boldsymbol{\beta}$ & t & Sig \\
\hline (Constant) & 0.125 & 0.022 & & 5.648 & 0.000 \\
\hline Functionality and layout & 0.546 & 0.022 & 0.538 & 24.601 & 0.000 \\
\hline Cosy and pleasant & 0.351 & 0.022 & 0.346 & 15.795 & 0.000 \\
\hline Enables concentration and comfortable & 0.267 & 0.022 & 0.263 & 12.034 & 0.000 \\
\hline Modern design & 0.104 & 0.022 & 0.102 & 4.656 & 0.000 \\
\hline Good daylight and outward facing & 0.217 & 0.022 & 0.213 & 9.754 & 0.000 \\
\hline Good artificial lighting & 0.229 & 0.022 & 0.225 & 10.296 & 0.000 \\
\hline R=0.765 & & & & \\
\hline
\end{tabular}




\subsection{Phase II: Identification of design elements with an impact on affective impressions}

\subsubsection{Obtaining groups of classroom design elements}

The factor analysis compiled the initial set of 20 design elements in the questionnaire to 4 independent factors, able to explain $56.68 \%$ of the variance (Table 5).

\begin{tabular}{|c|c|c|c|c|}
\hline & 1 & 2 & 3 & 4 \\
\hline Cladding & .797 & & & \\
\hline Walls & .785 & & & \\
\hline Ceiling & .739 & & & \\
\hline Decoration & .622 & & & \\
\hline Doors & .570 & & & \\
\hline Flooring & .552 & & & \\
\hline Furniture arrangement & & .832 & & \\
\hline Dimensions & & .823 & & \\
\hline Furniture & & .764 & & \\
\hline Location and access & & .619 & & \\
\hline Acoustic conditions & & & .758 & \\
\hline Noise level & & & .697 & \\
\hline Artificial lighting & & & .561 & \\
\hline Humidity conditions & & & .500 & .406 \\
\hline Equipment & & .442 & .472 & \\
\hline Layout of installations & & .335 & .447 & \\
\hline Daylight & & & & .797 \\
\hline Windows & .436 & & & .699 \\
\hline Ventilation conditions & & & .310 & .662 \\
\hline Thermal conditions & & & .475 & .483 \\
\hline$\%$ Variance explained & 16.52 & 15.13 & 13.67 & 11.36 \\
\hline Cronbach's Alpha & .821 & .820 & .750 & .742 \\
\hline
\end{tabular}

Table 5. Factor analysis of the design elements

- 1st factor: Includes the assessment of Finishes in the classroom. The design elements that contribute most to this factor are "claddings", "walls", "ceiling", "decoration", "doors" and "flooring". This factor explains $16.52 \%$ of the variance in the original variables.

- 2nd factor: Represents the assessment of the Personal work space available for the student to work in the classroom. Elements like "furniture arrangement", 
"dimensions", "furniture" and "location and access" are very significant in this factor. It explains $15.13 \%$ of the variance.

- 3rd factor: Represents the Interior environmental conditions of the classroom The attributes that make up this factor refer to interior conditions like "acoustic conditions", "noise level", "artificial lighting", "humidity conditions", "equipment (computers, blackboard, etc.)", "layout and installations (location of power sockets, telephone, ventilation grilles, etc.)". It explains $13.67 \%$ of the sample variance.

- 4th factor: Represents the assessment of the classroom through its Relationship with the outside with attributes such as "daylight", "windows", "ventilation conditions" and "thermal conditions". This factor explains $11.36 \%$ of sample variability.

Cronbach's Alpha value for the four dimensions or factors ranged from 0.74 to 0.82 (Table 5), showing that these scales have considerable reliability [68].

3.2.2. Analysis of the relationship between groups of design elements and affective impressions

The relationship between the affective factors of the classroom and the design attributes is established using a nonparametric Spearman correlation coefficient. The results are shown in Figure 2. In general, the results clearly show that design elements can generate certain affective impressions. Thus, the sensation of functionality and layout of the classroom is closely related to the space available for students to work in; the sensation that the classroom enables concentration and it is comfortable transmits to students is 
linked basically to the interior environmental conditions in the classroom; the perception of modern design is mainly related to the finishes in the classroom; the sensation that the classroom has good daylight and it is outward facing significantly relates to the factor that gathers the attributes of relationship with the outside, a factor which in turn, includes daylight; good artificial lighting mainly relates to the factor reflecting the interior environmental conditions in the classroom which includes artificial lighting. Finally, the sensation that it is a cosy and pleasant classroom is generated equally by all the design factors.

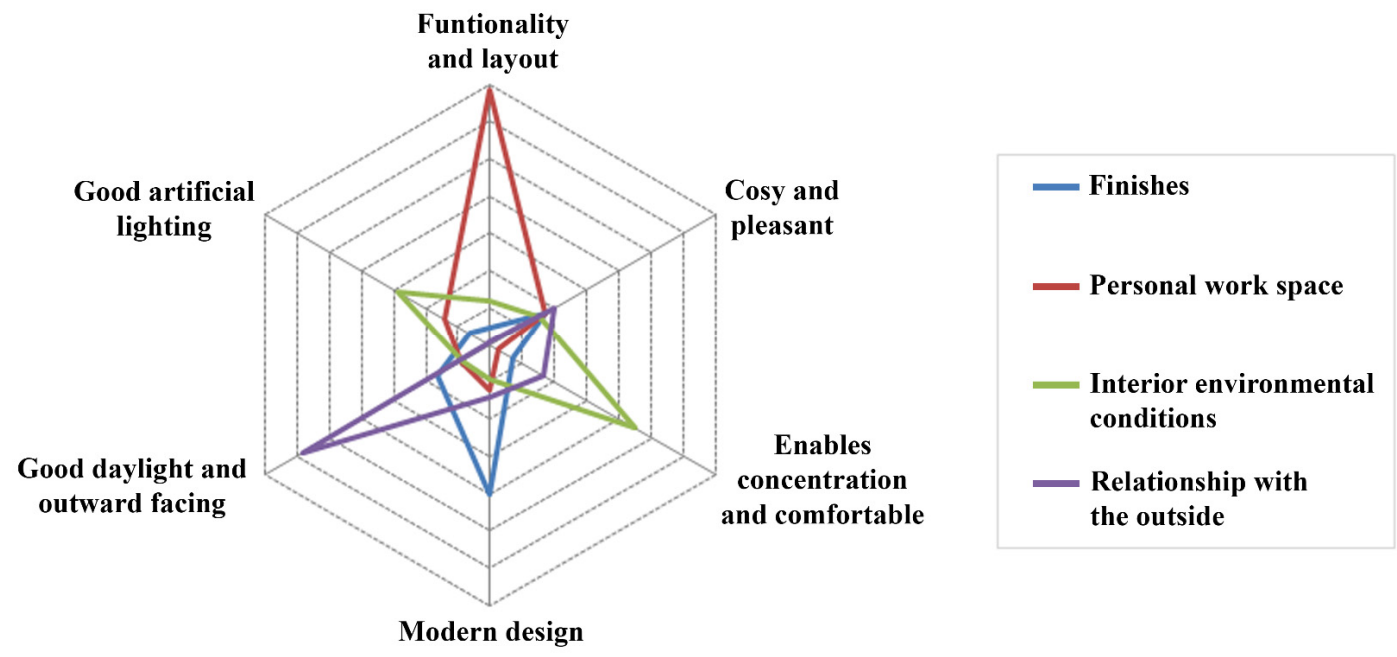

Fig. 2. Correlation analysis between affective impressions and groups of classroom design elements.

\section{DISCUSSION}

This paper aims to analyse students' affective responses to a classroom in their own words and to determine design criteria related to the overall assessment of university teaching rooms.

The results have significant implications at the levels of methodology and application. 
From the methodological point of view the most outstanding contribution is the application of Semantic Differential (in the framework of Kansei Engineering) to evaluate students' affective responses to their own classrooms. This is one of the main differences regarding other works based on the KE methodology. For example, ŞenolErdoğmuş’ work [65] comprised students' assessment regarding the contribution of each of the design elements to the motivation feeling. The key difference with our proposal is the incorporation of students' affective responses to the classroom environment, which allows us to identify the relation: design elements-affective response-classroom global assessment. This establishes another relevant difference regarding the works which have analysed the classroom environment according to its influence on the student's learning performance [7][9][11]. These works, although they incorporate the subjective part of students' perceptions, do not identify the affective structure that the classroom generates on the user. Only once that the users' affective dimensions or semantic axes have been obtained, it is possible to identify what design elements cause these semantic axes or perception variables.

Moreover, the attributes used to find relations with design parameters are defined not by experts, but by the students themselves. The studies consulted on the subjective evaluation of classrooms are based on concepts or attributes previously defined by experts or by the researchers themselves [11][42][43][44][45][69][70][71]. Thus, the mental scheme of students or non-experts was not taken into account when constructing the questionnaires. This approach could lead to erroneous results as the criteria and qualities reflected in the assessment questionnaires might not be recognised by users, thereby conditioning the evaluation process itself. In this work, the use of SD provides subjective evaluation scales adapted to the language of the students without expert intervention. 
As regards the contribution to application, the findings of this study provide important outcomes:

Firstly, the study has obtained students' affective structure in relation to their classroom. Six factors were identified which explain $64 \%$ of the variability in the sampled perception: 1st: functionality and layout (16.14\%); 2nd: cosy and pleasant (10.17\%); 3 th: concentration and comfort (10.16\%); 4th: modern design $(8.28 \%) ; 5$ th: good daylight and outward facing (8.21\%); 6th: good artificial lighting (6.21\%). The main contribution of these factors is that they match the students' conceptual scheme, and thus correspond more precisely to the concepts students use to differentiate between university classrooms. These independent factors are essential for studying, in a subsequent phase, the relationship between the physical parameters of classrooms with subjective judgements, as that relationship can hardly be established if users do not understand the concepts.

The results of this study are difficult to compare with other studies because there are very few applications of KE on the analysis of classroom environments. Nevertheless, it is possible to find a certain similarity between the affective response obtained in this study and the results reported in previous studies:

The axis functionality and layout, understood as the ability to understand the work space for students in the classroom, can be related to works which have used this dimension in a similar way, using expressions like "individualisation" [7] or "room layout and furniture"[11]. Other factors highlighted in the literature which may be 
related to this dimension are "seating arrangement" [15] or "spaciousness to avoid overcrowding" and "ability to adjust furniture"[72].

The axis cosy and pleasant appears to be linked to the sensation of "pleasure". Mehrabian and Russell [73][74] introduced this scale and it is one of the most commonly used to assess surroundings.

The axis concentration and comfort is an interesting combination of concepts as it is well known that variables like temperature influence concentration [75] and performance [76][77]. Many studies also report the relationship between comfort and environment noise [78][79] [42] [80] and temperature [43][81][82][83] $[84][85][86][87]$, mainly separately, but some studies analyse them together [88]. In the axis modern design the impressions of "new" and "good design" appear to reflect efforts to improve the state of educational infrastructure due to the growing body of research connecting the quality of school facilities to student performance [5]. In this case, this axis can be related to studies on the effect of building age or condition [89][72][89][90] of non-modernized versus modernized and refurbished buildings [91] or facilities maintenance [92][5] [40].

In the axis good daylight and outward facing similar expressions can be found in works on the evaluation of educational environments but generally not together. In the work by Barret et al., this dimension is labelled as "naturalness"[7] and combines the concepts of "light" and "links to nature" with those of "sound", "temperature" and "air quality". Curiously, in this dimension Barret et al. mention the concept "view out" which can be related with that of "exterior" which appears in this axis. Tanner [93] also studies separately the importance of "natural light" and "classrooms with views". In turn, this sensation can also be related to "view to outdoors" in the works by Douglas and Gifford [15]. Additionally, the concept "daylight" has appeared widely in previous 
studies on the evaluation of classroom environment and has been a subject of interest for many years [27]. Furthermore, the concept "daylight" can be found in many studies on the importance of natural light in teaching spaces [29][28][94][95] [96]. Finally, the axis good artificial lighting, is a significant dimension in works on the evaluation of classroom environment [97][98][99]. Some studies have examined classroom environment daylight and artificial lighting jointly [3][12][15]. The important contribution from the results of those studies, however, is that they establish that in students' conceptual scheme natural light and artificial light are two separate dimensions. Students perceive the sensation of natural light as being related to the exterior whereas they perceive artificial light as relating more to an interior concept combined with the sensation of the classroom as being well-lit. These findings are in line with other studies that have examined each axis separately [11]

Secondly, the regression analysis results indicate that although the set of factors are relevant in the overall evaluation of the classroom, efforts to improve the classroom environment should focus mainly on two aspects: improving classroom functionalitylayout and the sensation of cosy-pleasant. If we compare them with existing evidence from the literature these findings are in line with those reported by Yang et al. [11] where student perceptions of their learning environments were heavily reliant on spatial attributes (such as room layout and furniture). These results seem to be in line with Gifford [37] who claims that the physical aspects of a setting, such as furniture arrangement, room shape or size and allocation of spaces within the room, can influence its defensibility and how we orient ourselves within a given space. Moreover, Stamps [100] suggests that the ranges through which people can see or move through environments are extremely important and influence behaviour. He argued that safety is 
the most important function an organism can have in an environment; safety is intimately entwined with the ability to see (visual permeability) and move (locomotive permeability). In our case, all these perceptions of the classroom lie between the two main axes: functionality-layout and cosy-pleasant. The importance of the work space for students appears to be related to the fact that the space in a room delivers a silent message to students, where the flow and shift in distance between people is a large part of the communication process [16]. In this sense, Tanner's studies[93] already confirm the importance for the student of the existence of movement and circulation patterns, understood as places and spaces where people are free to move through without feeling confined or in a crowded environment. Furthermore, it is known that classroom spatial arrangements with well-defined areas can have a positive influence on students' social interaction and cooperation [101].

Thirdly, and after ordering the affective impressions in relation to their significance in the global evaluation, the impact of each classroom design element on students' affective impressions is obtained. Given the complexity of the stimulus, due to the amount of design elements in a classroom, initially groups of elements representative of design in a teaching classroom were obtained. These groups made up a total of four independent factors, able to explain $56.68 \%$ of the variance: 1st: Finishes (16.52\%); 2nd: Personal work space (15.13\%); 3th: Interior environmental conditions (13.67\%) and 4th: Relationship with the outside (11.36\%).

In general, it can be seen that one of the most important design factors is personal work space for students in the classroom, because it is the key element to generate the sensation of functionality and layout of the classroom, one of the most important axes in 
the global assessment. These results are in line with the findings reported by Yang [11] showing that student perceptions rely heavily on spatial attributes. Within this design factor one fundamental design element is the furniture and the way it is laid out. The literature presents a clearly positive effect of school furniture dimensions on students' performance and physical responses [102]. This affect may be because furniture has an important role in the maintenance of good sitting posture [103]. And in fact, the importance of seating for the classroom environment has been recognised [12]. Unsuitable classroom furniture can lead to poor sitting postures and bodily discomfort.

Interior environmental conditions in the classroom appear as the second most important design factor. This axis appears to assimilate to the one Baker [104] calls "ambient factor", recognising it as one of three components of the atmospheric attributes of interior spaces. This design factor is a relevant attribute for students as it is linked to the axis that reflects students' sensation of comfort and their ability to concentrate in the classroom. This finding is significant because this relationship combines all the attributes of interior environment quality (IEQ) in the classroom. According to these data, students' comfort, and ability to concentrate are significantly related to the classroom's interior environmental conditions. This finding is in line with ClementsCroome [105] who reports that schools fall within the category of buildings where high interior environmental quality (IEQ) can considerably improve occupants' ability to concentrate, learn, listen and make presentations.

The relationship with the outside is the third relevant design element in the assessment of a classroom and is mainly related to the sensation of good daylight and outward facing which gives an idea of the consistency of the results. The attribute "daylight" in 
classrooms has been linked with a positive impact on students' learning performance [8] and may be caused by the fact that our reactions, motivations, moods and sense of wellbeing are greatly impacted by the illumination of our surrounding environment [106]. The specific design element of windows may be related with some studies that established that people prefer rooms with windows to those without [107][108]. This finding is in line with the study by Matsuoka [32] which shows that views of abundant trees and shrubs from classroom windows are positively associated with student performance. In fact, he argued that a growing body of research has linked views of and access to nature with restoration from mental fatigue and stress reduction [109][110][111]. A clear contribution of this study is that students' conceptual scheme clearly differentiates between what is inside the classroom and what is outside. The interior conditions (acoustics, noise level, artificial lighting, humidity...) are linked to the sensation of comfort and concentration that students have inside the classroom and the relationship of the room with the outside (natural light, windows, ventilation, and thermal conditions) are related to the sensation that the classroom is well lit and outward facing.

Classroom finishes is the fourth most important design factor and is linked to the sensation that the classroom has a modern design and to a lesser extent with the sensation of cosy, of being well lit and outward facing. Chan [112] found student achievement to be higher in school buildings with modern facilities than in buildings with older facilities.

One possible limitation of the study is that the experiments took place in real classrooms. This could be a disadvantage because the possible combination of design 
elements that may influence perception is given by the availability of those combinations in the real classrooms. However, it was very interesting for the authors to work in actual classrooms where users are immersed $100 \%$ in a real experience. Nevertheless, in order to reduce the impact of this bias, the solution proposed by Kish [66] was adopted, which consists in including these variables in a random manner, assuming that chance will generate equivalent distributions of the units in all the variables of interest. Thus, although bias is still present, it is reduced. However, this limitation is not relevant in this stage of $\mathrm{KE}$, where the aim is to obtain a representation of the students' opinions regarding the university classroom environment and it must be as varied as possible.

\section{CONCLUSIONS}

This paper presents a new paradigm where the student is placed in the centre of the design process of the university classroom environment. This approach is based on the $\mathrm{KE}$ as the methodology capable of connecting the design elements of the classroom with the students' affective response, obtaining a better satisfaction and experience of the use of the space.

One significant methodological contribution is the use of SD as a tool for defining subjective evaluation scales adapted to the evaluators. It is important to identify these independent attributes so that, in a subsequent phase, the perceptions can be related to the physical parameters that determine them.

This methodological approach may be of interest for designers, engineers and architects seeking to develop new classrooms which attempt to satisfy students' specific expectations. 


\section{ACKNOWLEDGEMENTS}

This research was supported by Ministerio de Economía y Competitividad. Spain (project TIN2013-45736-R)

\section{REFERENCES}

[1] N.M. Jamaludin, N. Mahyuddin, F.W. Akashah, Assessment of Indoor Environmental Quality (IEQ): Students Well-Being in University Classroom with the Application of Landscaping, MATEC Web Conf. EDP Sci. 6 (2016) 61. doi:10.1051/matecconf/20166600061.

[2] V.A. Collet da Graça, D.C.C.K. Kowaltowski, J.R.D. Petreche, An evaluation method for school building design at the preliminary phase with optimisation of aspects of environmental comfort for the school system of the State São Paulo in Brazil, Build. Environ. 42 (2007) 984-999. doi:10.1016/j.buildenv.2005.10.020.

[3] R. Asiyai, Students' perception of the condition of their classroom physical learning environment and its impact on their learning and motivation, Coll. Stud. J. 48 (2014) 716-726.

[4] L. Scott-Webber, J. Abraham, M. Marini, Higher education classroom fail to meet needs of faculty and atudents, J. Inter. Des. 26 (2000) 16-34. doi:10.1111/j.19391668.2000.tb00356.x.

[5] C. Uline, M. Tschannen-Moran, The walls speak: The interplay of quality facilities, school climate, and student achievement, J. Educ. Adm. 46 (2008) 5573. doi:10.1108/09578230810849817.

[6] P. Temple, Learning spaces in higher education: an under-researched topic, London Rev. Educ. 6 (2008) 229-241. doi:10.1080/14748460802489363. 
[7] P. Barrett, F. Davies, Y. Zhang, L. Barrett, The impact of classroom design on pupils' learning: Final results of a holistic, multi-level analysis, Build. Environ. 89 (2015) 118-133. doi:10.1016/j.buildenv.2015.02.013.

[8] P. Barrett, Y. Zhang, J. Moffat, K. Kobbacy, A holistic, multi-level analysis identifying the impact of classroom design on pupils' learning, Build. Environ. 59 (2013) 678-689. doi:10.1016/j.buildenv.2012.09.016.

[9] C.K. Tanner, Explaining relationships among student outcomes and the school's physical environment, J. Adv. Acad. 19 (2008) 444-471. doi:10.4219/jaa-2008812.

[10] C.K. Tanner, The influence of school architecture on academic achievement, J. Educ. Adm. 38 (2000) 309-330. doi:10.1108/09578230010373598.

[11] Z. Yang, B. Becerik-Gerber, L. Mino, A study on student perceptions of higher education classrooms: Impact of classroom attributes on student satisfaction and performance, Build. Environ. $70 \quad$ (2013) 171-188. doi:10.1016/j.buildenv.2013.08.030.

[12] M.C. Hill, K.K. Epps, The impact of physical classroom environment on student satisfaction and student evaluation of teaching in the university environment, Acad. Educ. Leadersh. J. 14 (2010) 65-79.

[13] N. Gislason, Architectural design and the learning environment: A framework for school design research, Learn. Environ. Res. 13 (2010) 127-145. doi:10.1007/s10984-010-9071-x.

[14] S. Higgins, E. Hall, K. Wall, P. Woolner, C. McCaughey, The Impact of School Environments: A literature review, 2005.

[15] D. Douglas, R. Gifford, Evaluation of the physical classroom by students and professors: a lens model approach, Educ. Res. 43 (2001) 295-309. 
doi:10.1080/00131880110081053.

[16] E. Duncanson, Classroom space: right for adults but wrong for kids, Educ. Facil. Plan. 38 (2003) 24-28.

[17] L.T. Wong, K.W. Mui, P.S. Hui, A multivariate-logistic model for acceptance of indoor environmental quality (IEQ) in offices, Build. Environ. 43 (2008) 1-6. doi:10.1016/j.buildenv.2007.01.001.

[18] V. De Giuli, O. Da Pos, M. De Carli, Indoor environmental quality and pupil perception in Italian primary schools, Build. Environ. 56 (2012) 335-345. doi:10.1016/j.buildenv.2012.03.024.

[19] S. Hoque, B. Weil, The Relationship between comfort perceptions and academic performance in university classroom buildings, J. Green Build. 11 (2016) 108-117. doi:10.3992/jgb.11.1.108.1.

[20] A. Uzelac, N. Gligoric, S. Krco, A comprehensive study of parameters in physical environment that impact students' focus during lecture using Internet of Things, Comput. Human Behav. 53 (2015) 427-434. doi:10.1016/j.chb.2015.07.023.

[21] I. Sarbu, C. Pacurar, Experimental and numerical research to assess indoor environment quality and schoolwork performance in university classrooms, Build. Environ. 93 (2015) 141-154. doi:10.1016/j.buildenv.2015.06.022.

[22] M.C. Lee, K.W. Mui, L.T. Wong, W.Y. Chan, E.W.M. Lee, C.T. Cheung, Student learning performance and indoor environmental quality (IEQ) in air-conditioned university teaching rooms, Build. Environ. 49 (2012) 238-244. doi:10.1016/j.buildenv.2011.10.001.

[23] U. Haverinen-Shaughnessy, R.J. Shaughnessy, E.C. Cole, O. Toyinbo, D.J. Moschandreas, An assessment of indoor environmental quality in schools and its association with health and performance, Build. Environ. 93 (2015) 35-40. 
doi:10.1016/j.buildenv.2015.03.006.

[24] M. Turunen, O. Toyinbo, T. Putus, A. Nevalainen, R. Shaughnessy, U. HaverinenShaughnessy, Indoor environmental quality in school buildings, and the health and wellbeing of students, Int. J. Hyg. Environ. Health. 217 (2014) 733-739. doi:10.1016/j.ijheh.2014.03.002.

[25] E. Simons, S.-A. Hwang, E.F. Fitzgerald, C. Kielb, S. Lin, The Impact of School Building Conditions on Student Absenteeism in Upstate New York, Am. J. Public Health. 100 (2010) 1679-1686. doi:10.2105/AJPH.2009.165324.

[26] D.G. Shendell, R. Prill, W.J. Fisk, M.G. Apte, D. Blake, D. Faulkner, Associations between classroom $\mathrm{CO} 2$ concentrations and student attendance in Washington and Idaho, Indoor Air. 14 (2004) 333-341. doi:10.1111/j.1600-0668.2004.00251.x.

[27] W. Wu, E. Ng, A review of the development of daylighting in schools, Light. Res. Technol. 35 (2003) 111-125. doi:10.1191/1477153503li072oa.

[28] Heschong Mahone Group, Summary of Daylighting in Schools: Reanalysis Report, 2003.

[29] T. Kim, W. Hong, H. Kim, Daylight evaluation for educational facilities established in high-rise housing complexes in Daegu, South Korea, Build. Environ. 78 (2014) 137-144. doi:10.1016/j.buildenv.2014.04.026.

[30] L. Bellia, F. Bisegna, G. Spada, Lighting in indoor environments: Visual and nonvisual effects of light sources with different spectral power distributions, Build. Environ. 46 (2011) 1984-1992. doi:10.1016/j.buildenv.2011.04.007.

[31] R.S. Ulrich, Visual landscapes and psychological well-being, Landsc. Res. 4 (1979) 17-23. doi:10.1080/01426397908705892.

[32] R.H. Matsuoka, Student performance and high school landscapes: Examining the links, Landsc. Urban Plan. $97 \quad$ (2010) 273-282. 
doi:10.1016/j.landurbplan.2010.06.011.

[33] J.A. Benfield, G.N. Rainbolt, P.A. Bell, G.H. Donovan, Classrooms with nature views: Evidence of differing student perceptions and behaviors, Environ. Behav. 47 (2015) 140-157. doi:10.1177/0013916513499583.

[34] N.J. Stone, Designing effective study environments, J. Environ. Psychol. 21 (2001) 179-190. doi:10.1006/jevp.2000.0193.

[35] M.A. Read, A.I. Sugawara, J.A. Brandt, Impact of space and color in the physical environment on preschool children's cooperative behavior, Environ. Behav. 31 (1999) 413-428. doi:10.1177/00139169921972173.

[36] N. Camgöz, C. Yener, D. Güvenç, Effects of hue, saturation, and brightness: Part 2 - Attention, Color Res. Appl. 29 (2004) 20-28. doi:10.1002/col.10214.

[37] R. Gifford, Environmental Psychology: Principles \& Practice, Optimal books, Colville, WA, 2007.

[38] K. Engelbrecht, The Impact of Color on Learning, NeoCon Perkins Will. (2003) $1-5$.

[39] A. Gilavand, M. Hosseinpour, Investigating the impact of educational spaces painted on learning and educational achievement of elementary students in Ahvaz, Southwest of Iran, Int. J. Pediatr. 4 (2016) 1387-1396. doi:10.22038/ijp.2016.6500.

[40] J. Bailey, A synthesis of studies pertaining to building conditions, student achievement, student behavior, and student attitude, Virginia Tech, 2009.

[41] D.J. O’Neill, A.D. Oates, The impact of school facilities on student achievement, behavior, attendance, and teacher turnover rate in Central Texas middle schools, Educ. Facil. Plan. 36 (2001) 14-22. doi:10.16953/deusbed.74839.

[42] P.H.T. Zannin, C.R. Marcon, Objective and subjective evaluation of the acoustic 
comfort in classrooms, Appl. Ergon. 38 (2007) 675-680. doi:10.1016/j.apergo.2006.10.001.

[43] S.P. Corgnati, M. Filippi, S. Viazzo, Perception of the thermal environment in high school and university classrooms: Subjective preferences and thermal comfort, Build. Environ. 42 (2007) 951-959. doi:10.1016/j.buildenv.2005.10.027.

[44] C. Buratti, P. Ricciardi, Adaptive analysis of thermal comfort in university classrooms: Correlation between experimental data and mathematical models, Build. Environ. 44 (2009) 674-687. doi:10.1016/j.buildenv.2008.06.001.

[45] M.A. Nico, S. Liuzzi, P. Stefanizzi, Evaluation of thermal comfort in university classrooms through objective approach and subjective preference analysis, Appl. Ergon. 48 (2015) 111-120. doi:10.1016/j.apergo.2014.11.013.

[46] S. Ishihara, K. Ishihara, M. Nagamachi, Y. Matsubara, An analysis of Kansei structure on shoes using self-organizing neural networks, Int. J. Ind. Ergon. 19 (1997) 93-104. doi:10.1016/S0169-8141(96)00006-6.

[47] C.E. Osgood, G.J. Suci, P.H. Tannenbaum, The Measurement of Meaning, University of Illinois Press, Urbana and Chicago, 1957.

[48] M. Nagamachi, Kansei Engineering: A new ergonomic consumer-oriented technology for product development, Int. J. Ind. Ergon. 15 (1995) 3-11. doi:10.1016/0169-8141(94)00052-5.

[49] M. Nagamachi, Kansei Engineering, Kaibundo Publisihing, Tokyo, 1989.

[50] Y. Akao, History of Quality Function Deployment in Japan, Hanser Publishers, 1990.

[51] L. Cohen, Quality Function Deployment. How to Make QFD Work for You, Addison-Wesley, Massachusetts, 1995.

[52] P.E. Green, V. Srinivasan, Conjoint analysis in consumer research: Issues and 
outlook, J. Consum. Res. 5 (1978) 103-123.

[53] S.T.W. Schütte, J. Eklund, J.R.C. Axelsson, M. Nagamachi, Concepts, methods and tools in Kansei Engineering, Theor. Issues Ergon. Sci. 5 (2004) 214-231. doi:10.1080/1463922021000049980.

[54] S. Takebuchi, T. Nakamura, H. Asami, K. Amasaka, The automobile exterior color design approach model, J. Japan Ind. Manag. Assoc. 62 (2012) 303-310.

[55] C. Llinares, A. Page, Application of product differential semantics to quantify purchaser perceptions in housing assessment, Build. Environ. 42 (2007) 24882497. doi:10.1016/j.buildenv.2006.06.012.

[56] C. Llinares, A.F. Page, Differential semantics as a Kansei Engineering tool for analysing the emotional impressions which determine the choice of neighbourhood: The case of Valencia, Spain, Landsc. Urban Plan. 87 (2008) 247257. doi:10.1016/j.landurbplan.2008.06.006.

[57] Y. Matsubara, M. Nagamachi, Hybrid Kansei engineering system and design support, Int. J. Ind. Ergon. 19 (1997) 81-92. doi:10.1016/S0169-8141(96)000054.

[58] S. Nagasawa, Fuzzy sensory evaluation of condominia's facade, in: Proc. 1995 IEEE. Int. Jt. Conf. Fourth IEEE Int. Conf. Fuzzy Syst. Second Int. Fuzzy Eng. Symp., IEEE, 1995: pp. 503-508. doi:10.1109/FUZZY.1995.409733.

[59] C. Llinares, A. Page, J. Llinares, An approach to defining strategies for improving city perception. Case study of Valencia, Spain, Cities. 35 (2013) 78-88. doi:http://dx.doi.org/10.1016/j.cities.2013.06.009.

[60] J. Kang, M. Zhang, Semantic differential analysis of the soundscape in urban open public spaces, Build. Environ. $45 \quad$ (2010) 150-157. doi:10.1016/j.buildenv.2009.05.014. 
[61] M. Galiana, C. Llinares, Á. Page, Subjective evaluation of music hall acoustics: Response of expert and non-expert users, Build. Environ. 58 (2012) 1-13. doi:10.1016/j.buildenv.2012.06.008.

[62] M. Galiana, C. Llinares, Á. Page, Impact of architectural variables on acoustic perception in concert halls, J. Environ. Psychol. 48 (2016) 108-119. doi:10.1016/j.jenvp.2016.09.003.

[63] K. Nishikawa, Y. Hirasawa, M. Nagamachi, Evaluation of thermal environment based on Kansei engineering, Japanese J. Ergon. 33 (1997) 289-296. doi: $10.5100 /$ jje.33.289.

[64] K. Nishikawa, Y. Hirasawa, A study of the effects of a thermal environment created by a floor heating system on learning efficiency, Japanese J. Ergon. 35 (1999) 177-184. doi:10.5100/jje.35.177.

[65] E.K. Şenol-Erdoğmuş, Using Kansei Engineering to improve the physical environment of the classroom, New Educ. Rev. 23 (2011) 245-253.

[66] L. Kish, Survey Sampling, John Wiley and Sons, New York, USA, 1995.

[67] J. Terninko, Step-by-Step QFD: Customer-Driven Product Design, Second Ed., Boca Raton, Florida, 1997.

[68] D.L. Streiner, Starting at the beginning: An introduction to coefficient alpha and internal consistency, J. Pers. Assess. $80 \quad$ (2003) 99-103. doi:10.1207/S15327752JPA8001_18.

[69] S.M. Kennedy, M. Hodgson, L.D. Edgett, N. Lamb, R. Rempel, Subjective assessment of listening environments in university classrooms: Perceptions of students, J. Acoust. Soc. Am. 119 (2006) 299. doi:10.1121/1.2139629.

[70] A. Astolfi, F. Pellerey, Subjective and objective assessment of acoustical and overall environmental quality in secondary school classrooms., J. Acoust. Soc. 
Am. 123 (2008) 163-173. doi:10.1121/1.2816563.

[71] S.S. Yahya, A.R.M. Ariffin, M.A. Ismail, Factors Contributing to Occupants' Comfort: A Survey among Occupants of Academic Buildings in a Public University, in: Int. Conf. Ind. Eng. Oper. Manag., Bali, Indonesia, 2014: pp. 30903098 .

[72] H.K. Wilson, A. Cotgrave, Factors that influence students' satisfaction with their physical learning environments, Struct. Surv. 34 (2016) 256-275. doi:10.1108/SS01-2016-0004.

[73] A. Mehrabian, J.A. Russell, An Approach to Environmental Psychology, M.I.T. Press, 1974.

[74] N. Gurbindo, J.E. Ortega, Adaptación de las escalas de placer, activación y dominancia de Mehrabian y Russell en sujetos hispanoparlantes, Rev. Psicol. Soc. 4 (1989) 179-183. doi:10.1080/02134748.1989.10821601.

[75] E. Howarth, M.S. Hoffman, A multidimensional approach to the relationship between mood and weather, Br. J. Psychol. 75 (1984) 15-23. doi:10.1111/j.20448295.1984.tb02785.x.

[76] M.J. Mendell, G.A. Heath, Do indoor pollutants and thermal conditions in schools influence student performance? A critical review of the literature, Indoor Air. 15 (2005) 27-52. doi:10.1111/j.1600-0668.2004.00320.x.

[77] P. Wargocki, D. Wyon, The effects of moderately raised classroom temperatures and classroom ventilation rate on the performance of schoolwork by children, HVAC\&R Res. 13 (2007) 193-220. doi:10.1080/10789669.2007.10390951.

[78] P. Leśna, E. Skrodzka, Subjective evaluation of classroom acoustics by teenagers vs. reverberation time, Acta Phys. Pol. A. 118 (2010) 115-117.

[79] J. Radosz, Global index of the acoustic quality of classrooms, Arch. Acoust. 38 
(2013) 159-168. doi:10.2478/aoa-2013-0018.

[80] D.L. Valente, H.M. Plevinsky, J.M. Franco, E.C. Heinrichs-Graham, D.E. Lewis, Experimental investigation of the effects of the acoustical conditions in a simulated classroom on speech recognition and learning in children, J. Acoust. Soc. Am. 131 (2012) 232. doi:10.1121/1.3662059.

[81] Z.S. Zomorodian, M. Tahsildoost, M. Hafezi, Thermal comfort in educational buildings: A review article, Renew. Sustain. Energy Rev. 59 (2016) 895-906. doi:10.1016/j.rser.2016.01.033.

[82] A.K. Mishra, M. Ramgopal, A thermal comfort field study of naturally ventilated classrooms in Kharagpur, India, Build. Environ. 92 (2015) 396-406. doi:10.1016/j.buildenv.2015.05.024.

[83] R. de Dear, J. Kim, C. Candido, M. Deuble, Adaptive thermal comfort in Australian school classrooms, Build. Res. Inf. 43 (2015) 383-398. doi:10.1080/09613218.2015.991627.

[84] Y. Wang, J. Kuckelkorn, F.-Y. Zhao, D. Liu, A. Kirschbaum, J.-L. Zhang, Evaluation on classroom thermal comfort and energy performance of passive school building by optimizing HVAC control systems, Build. Environ. 89 (2015) 86-106. doi:10.1016/j.buildenv.2015.02.023.

[85] I. Nam, J. Yang, D. Lee, E. Park, J.-R. Sohn, A study on the thermal comfort and clothing insulation characteristics of preschool children in Korea, Build. Environ. 92 (2015) 724-733. doi:10.1016/j.buildenv.2015.05.041.

[86] D. Teli, M.F. Jentsch, P.A.B. James, The role of a building's thermal properties on pupils' thermal comfort in junior school classrooms as determined in field studies, Build. Environ. 82 (2014) 640-654. doi:10.1016/j.buildenv.2014.10.005.

[87] D. Teli, P.A.B. James, M.F. Jentsch, Thermal comfort in naturally ventilated 
primary school classrooms, Build. Res. Inf. 41 (2013) 301-316. doi:10.1080/09613218.2013.773493.

[88] E.L. Krüger, P.H.T. Zannin, Acoustic, thermal and luminous comfort in classrooms, Build. Environ. $39 \quad$ (2004) 1055-1063. doi:10.1016/j.buildenv.2004.01.030.

[89] L.E. Maxwell, S.L. Schechtman, The role of objective and perceived school building quality in student academic outcomes and self-perception, Child. Youth Environ. 22 (2012) 23-51. doi:10.7721/chilyoutenvi.22.1.0023.

[90] V. Durán-Narucki, School building condition, school attendance, and academic achievement in New York City public schools: A mediation model, J. Environ. Psychol. 28 (2008) 278-286. doi:10.1016/j.jenvp.2008.02.008.

[91] L.E. Maxwell, School Building Renovation and Student Performance: One District's Experience, (1999).

[92] C. Vidalakis, M. Sun, A. Papa, The quality and value of higher education facilities: a comparative study, Facilities. 31 (2013) 489-504. doi:10.1108/F-10-2011-0087.

[93] C.K. Tanner, Effects of school design on student outcomes, J. Educ. Adm. 47 (2009) 381-399. doi:10.1108/09578230910955809.

[94] S.S. Korsavi, Z.S. Zomorodian, M. Tahsildoost, Visual comfort assessment of daylit and sunlit areas: A longitudinal field survey in classrooms in Kashan, Iran, Energy Build. 128 (2016) 305-318. doi:10.1016/j.enbuild.2016.06.091.

[95] A. Meresi, Evaluating daylight performance of light shelves combined with external blinds in south-facing classrooms in Athens, Greece, Energy Build. 116 (2016) 190-205. doi:http://dx.doi.org/10.1016/j.enbuild.2016.01.009.

[96] C.F. Reinhart, D.A. Weissman, The daylit area - Correlating architectural student assessments with current and emerging daylight availability metrics, Build. 
Environ. 50 (2012) 155-164. doi:10.1016/j.buildenv.2011.10.024.

[97] P.J.C. Sleegers, N.M. Moolenaar, M. Galetzka, A. Pruyn, B.E. Sarroukh, B. van der Zande, Lighting affects students' concentration positively: Findings from three Dutch studies, Light. Res. Technol. 45 (2012) 159-175. doi:10.1177/1477153512446099.

[98] M.S. Mott, D.H. Robinson, A. Walden, J. Burnette, A.S. Rutherford, Illuminating the effects of dynamic lighting on student learning, SAGE Open. 2 (2012). doi:10.1177/2158244012445585.

[99] M. Winterbottom, A. Wilkins, Lighting and discomfort in the classroom, J. Environ. Psychol. 29 (2009) 63-75. doi:10.1016/j.jenvp.2008.11.007.

[100] A.E. Stamps, Effects of permeability on perceived enclosure and spaciousness, Environ. Behav. 42 (2010) 864-886. doi:10.1177/0013916509337287.

[101] G.T. Moore, Effects of the spatial definition of behavior settings on children's behavior: A quasi-experimental field study, J. Environ. Psychol. 6 (1986) 205231. doi:10.1016/S0272-4944(86)80023-8.

[102] H. Castellucci, P. Arezes, J. Molenbroek, R. de Bruin, C. Viviani, The influence of school furniture on students' performance and physical responses: Results of a systematic review., $\quad$ Ergonomics. $139 \quad$ (2016) $1-51$. doi: $10.1080 / 00140139.2016 .1170889$.

[103] G. Panagiotopoulou, K. Christoulas, A. Papanckolaou, K. Mandroukas, Classroom furniture dimensions and anthropometric measures in primary school, Appl. Ergon. 35 (2004) 121-128. doi:10.1016/j.apergo.2003.11.002.

[104] J. Baker, The role of the environment in marketing services: The consumer perspective, in: J. Czepiel (Ed.), Serv. Chall. Integr. Compet. Advant., American Marketing Association, Chicago, 1986: pp. 79-84. 
[105] D.J. Clements-Croome, H.B. Awbi, Z. Bakó-Biró, N. Kochhar, M. Williams, Ventilation rates in schools, Build. Environ. 43 (2008) 362-367. doi:16/j.buildenv.2006.03.018.

[106] N.C. Ruck, Building Design and Human Performance, New York, NY (USA); Van Nostrand Reinhold Co., 1989.

[107] S. Verderber, Dimensions ofperson-window transactions in the hospital environment, Environ. Behav. $18 \quad$ (1986) 450-466. doi:10.1177/0013916586184002.

[108] E. Ne'Eman, Visual aspects of sunlight in buildings, Light. Res. Technol. 6 (1974) 159-164. doi:10.1177/096032717400600304.

[109] Heschong Mahone Group, Windows and Classrooms: A Study of Student Performance and the Indoor Environment, Fair Oaks, California, 2003.

[110] A.F. Taylor, F.E. Kou, W.C. Sullivan, Views of Nature and Self-Discipline: Evidence From Inner City Children, J. Environ. Psychol. 22 (2002) 49-63. doi:10.1006/jevp.2001.0241.

[111] C.M. Tennessen, B. Cimprich, Views to nature: Effects on attention, J. Environ. Psychol. 15 (1995) 77-85. doi:10.1016/0272-4944(95)90016-0.

[112] T.C. Chan, The Impact of School Building Age on Pupil Achievement, University of Georgia, Athens, GA., 1996. 